\title{
A Constraint-based Case Frame Lexicon
}

\author{
Kemal Oflazer and Okan Yllmaz \\ Department of Computer Engincering and Information Science \\ Bilkent University \\ Bilkent, Ankara 06533, T'urkey \\ $\{$ ko, okan\}@cs.bilkent. edu.tr
}

\begin{abstract}
We present a constraint-based case frame lexicon architecture for bi-directional mapping between a syntactic case frame and a semantic frame. The lexicon uses a semantic sense as the basic unit and employs a multi-tiered constraint structure for the resolution of syntactic information into the appropriate senses and/or idiomatic usage. Valency changing transformations such as morphologically marked passivized or causativized forms are handled via lexical rules that manipulate case frames templates. The system has been implemented in a typedfeature system and applied to Turkish.
\end{abstract}

\section{$1 \quad$ Introduction}

Recent advances in theoretical and practical aspects of fcature and constraint-based formalisms for representing linguistic information have fostored research on the use of such formalisms in the design and implementation of computational lexicons (Briscoe et al., 1993). Case frame approach has been the representation of choice especially for languages with frce constituent order, explicit case marking of noun phrases and embedded clauses filling nominal syntactic roles. The semantics of such syntactic role fillers are usually determined by their lexical, semantic and morphosyntactic propertics, instead of position in the sentence. In this paper, wo prosent an approach to building a constraint-based case frame lexicon for use in natural language processing in 'Turkish.

$\Lambda$ number of observations that we have made on Thrkish have indicated that we have to go beyond the traditional transitive and intransitive distinction, and utilize a framework where verb valence is considered as the obligatory co-existence of an arbitrary subset of possible arguments along with the obligatory exclusion of certain others, relative to a verb sense. Additional morphosyntactic, lexical and semantic selectional constraints are utilized to map a given syntactic argument structure to a specific verb sense. In recent years, therc have been several studies on constraint-based lexicons. Russell et al. (1993) propose an approach to multiple default inheritance for unification-based lexicon. In another study by Irascarides et al. (1995), an ordered approach to default unification is suggested. de Paiva (1993) formalizes the system of well-formed typed feature structures. In this study, type hierarchies and relations are mathematically defined. They also formalize unification and generalization operators betweon the feature structures, along with defining well-formedness notion that we use in our system.

\section{Representing Case Frame Information}

In Turkish, (and possibly in many other languages) vorbs often convey sevcral meanings (some totally unrelated) when they are used with subjects, objects, obliquc objects, adverbial adjuncts, with certain lexical, morphological, and semantic foatures, and co-occurrence restrictions. In addition to the usual sense variations due to selectional restrictions on verbal arguments, in most cases, the meaning conveyed by a case frame is idiomatic, with subtle constraints. For example, the 'Turkish verb ye (eat), when used with a direct object noun phrase whose head is:

1. para (money), with no case or possessive markings and a human subject, means to accept bribe,

2. para (money), with a non-human subject, moans to cost a lot,

3. para (or any other NP whose head is ontologically IS-A money, e.g., dolar, mark, ete.) with obligalory accusative marking and oplional possessive marking, means to spend money,

4. kafa (head) with obligatory accusative marking and no possessive marking, means to get mentally deranged,

5. hak (right) with optional accusative and possessive markings, means to be unfair, 
6. bas (head, ef. 4) (ol any NP' whose head is ontologically IS- $\Lambda$ human) with optional accusative and optional possessive marking (obligatory only with bass), means to waste or demote a person.

On the other liand:

1. if an ablative case-marked oblique object deuoting an colible entity is present, then there should not be any direct olject, and the verb means to eal a pice of (the cdible (oblique) object), or

2. if the ablative case-matked oblique object does not denote something edible, but rather a container, then the sense maps to to cat out of, with the optional direct (edible) object denoting the object caten.

Clearly such usage has impact on thematic rolo assigmments to various role fillers, and even on the syutactic behavior of the verl) in question (Briscoe and (arroll, 1994). For instance, for the third and fourth cases above where the object has to be obligalorily case-marked accusative, a passive form would not be grammatical for the sense conveyod, although syntactically ye (eat) is a transitive verls.

Sometimes verbs require diflerent combinations of arguments, or explicitly require that certain arguments not be present. For instance, the verb sas requires different kinds of arguments deponding on the sense, obligatorily excluding other arguments:

1. an ablative case-marked oblique object and with no other object in the case frame sas incius to deviate from,

2. a dalive case-marked oblique object and with no other object, sas means to be surprised at,

3. an accusative case-marked direct object with no olher object, sas means to be confused about.

$A s$ a final example, when the verb tut (catch/loold) is used with an obligutory $3^{\text {rd }}$ person singular agreement and active voice, and the subject is a (nominalized) $S$ with a verb form of fulure participle, then the sense conveyed by the top level case frame is to feel like doing the predication indicated by the subject $S$ 's case frame, with the agent being the subject of this embedded clause.

As illustrated in these examples, verb sense idiomalic usage resolution has to be dealt with in a principles way and not by pattern matehing (e.g., as in 'I'schichold (1995)), when the language has a free word order, whore pattern matching approaches could fail. In this paper, wo present a unification-beused approach to a constraint-based case frame lexicon, in which one single mechanism deals with both problems uniformly. The essential function of onr lexicon is to map) bidirectionally between a case frame containing information that is syntactic, and a semantic frame which captures the predication denoted by the case frame along with information about who fills what thematic role in that predication.

\section{The Lexicon Architecture}

In this section wo present an overview of structure of lexicon entries and the nature of the constraints. 'The basic unit in the lexicon is a sense which is the information denoting some indivisible predication along with the thematic roles involved. We generate the case frame of each sense by unifying a set of co-occurrence, morphological, synlactic, semantic, and lexical constraints on verbs, their arguments. 'The lexicon is implemented in 'TFS (Kuhn, 1993) by the disjunction of the sonses delined by mifying wf-case-frame (well-formed case frame) with each sense:

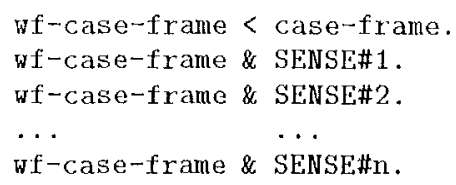

\subsection{Lexicon Entries}

Fach verb sense entry in the lexicon has the steructure shown by the feature structure matrix in Figure 1 .

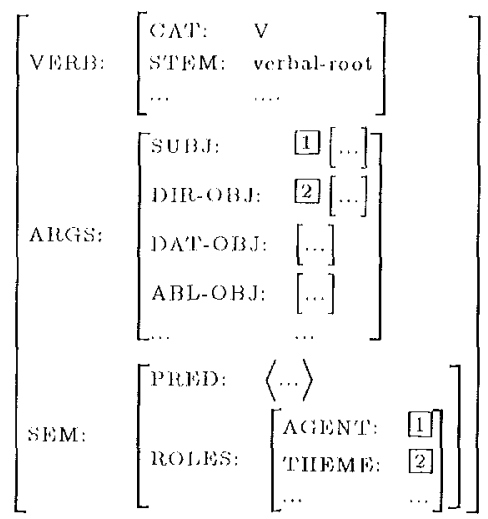

Figure 1: Structure of a case frame lexicon entry.

'The fealure structure for each syntactic arg'ument contains information about the morphological and syntactic structure of the syntactic constitucnt, such as part-of-specch, agreement, case, possessive markers, and additional morphological markings such as verb form, (e.g., infinitive, participle, elc.), voice (e.g., active, passive, causative, reflexive, reciprocal, ete.) for cmbedded S's, along with their own case frames. 'This structure is similar to the structure proposed in Lascarides $\mathrm{ct}$ al. (1995). IIowever, instead of classifying argument structures as simply transitive, intransitive, cte., we need to consider all relevant elements of the power set of possible arguments. For Turkish, the syntactic constituents that we have chosen to in- 


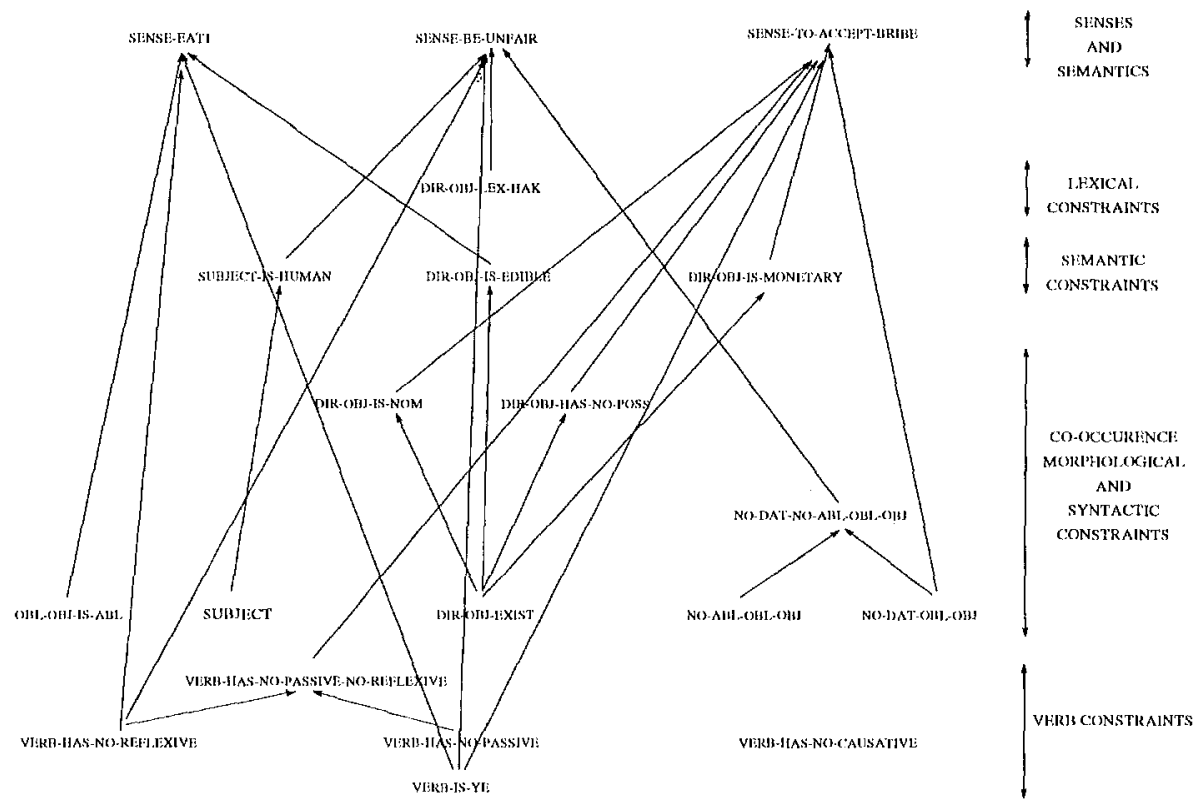

Figure 2: The portion of the constraint structure for a portion of the the Turkish verb "ye".

clude in the argument slot (for a verb in active voice) are the following:

- subject (nominative NP) ${ }^{1}$

- direct object (nominative or accusative casemarked NP),

- oblique objects (ablative, dative, locative case-marked NP),

- beneficiary object (dative case-marked NP, or PP with a certain PFORM),

- instrument object (instrumental case-marked NP or PP with a certain PFORM),

- value object (dative case-marked NP or PP with a certain PFORM).

In general, there may be more than one instantiation of the SEM frame for a given instantiated set of case frame arguments (and vice versa). For instance, for the ye verb discussed above, the argument structure for the third case giving rise to the meaning to get mentally deranged may conceivably give rise to a literal meaning in a rather improbable context (such as eating the head of a fish at dinner - much in the spirit of the two interpretations of the English idiom kick the bucket), or the same semantics may be expressed by a different surface form.

\subsection{Constraint Architecture}

We express constraints on the arguments in the case frame of a verb via a 5-tier constraint hierarchy sharing constraints among the specification of other constraints and sense definitions, whenever possible:

\footnotetext{
${ }^{1} \mathrm{NP}^{\prime} \mathrm{s}$ that have no case-marking in 'Turkish.
}

1. Constraints on verb features that describe any relevant constraints on the morphological fcatures of the verb, such as agreement or voice markers.

2. Constraints on morphological features that describe any obligatory constraints on the arguments, such as case-marking, verb form (in the case of embedded clauses), etc.

3. Constraints on argument co-occurrence that cxpress obligatory argument co-occurrence constraints along with constraints that indicate when cortain arguments should not occur in order resolve a sense.

4. Lexical constraints that indicate any specific constraints on the heads of the arguments in order to convey a certain sense, and usually constrain the stem of the head noun to be a certain lexical form, or one of a small set of lexical forms.

5. Semantic Constraints that indicate semantic selectional restriction constraints that may resolved using a companion ontological database (again implemented in TFS) in which we model the world by defining semantic categories, such as human, thing, nonliving object, living object, etc., along the lines described by Nagao et al. (1985).

Figure 2 illustrates the simplified form of the constraint-sense mapping of the verb ye (eal).

\subsection{Valency Changing Transformations}

As we have already stated, we cncode senses of verbs in active voice unless a verb has an idiomatic usage with obligatory passive, causative and/or 
reflexive voices. ${ }^{2}$ In order to handle these valency changing transformations, we define lexical rules as shown in Figure 3.

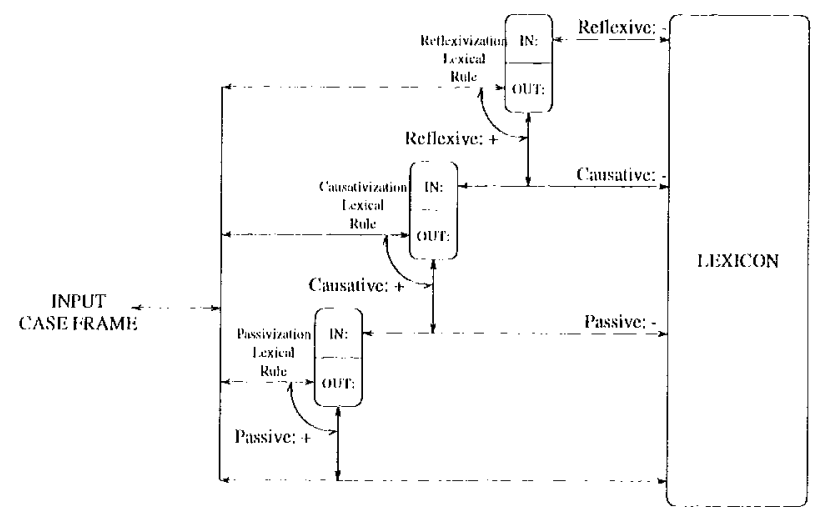

l'igure 3: Valency transformations using lexical rules.

This figure describes how a given case frame with its syntactic constituents is processed by a sequence of lexical rules each stripping off a certain voice marker and then attempting unification with the lexicon for any possible sense resolution. 'Ihe order of lexical rules in this figure reflects the reverse orker of voice markers in 'Turkish verbal morphology. ${ }^{3}$ So a givon case frame may have to go through three lexical rules until it finds a unifying entry in the lexicon. Unifications before going through all lexical rules are for (possibly idiomatic) senses which explicitly recuire various voice markings. 'I'wo additional constituents are added via these lexical rules. 'The AGN-OBJ (agentive object), denotes the equivalent of the by-object in passive sentences. 'The subject of the sentencess a causative voice marked verb is indicated by CAUSER in the semantics frame. Onr current implementation does not deal with multiple causative voice markings (which 'I'urkish allows), or with the rather tricky surface case change of the object of causation depending on the transitivity of the causativized verb. In the examples and sample rules below, a voice marker can take one of three values: (i) +: indicates the voice marker has to bo taken. (ii) - : indicates the voice marker is not taken (iii) nil: indicates the voice marker must not be laken; this is used only in the sense definitions in the lexicon and can unify with - but not, with + .

\footnotetext{
${ }^{2}$ for instance: birine vurmak vis.

${ }^{3}$ We have not dealt with the reciprocal/collective voice marker yet.
}

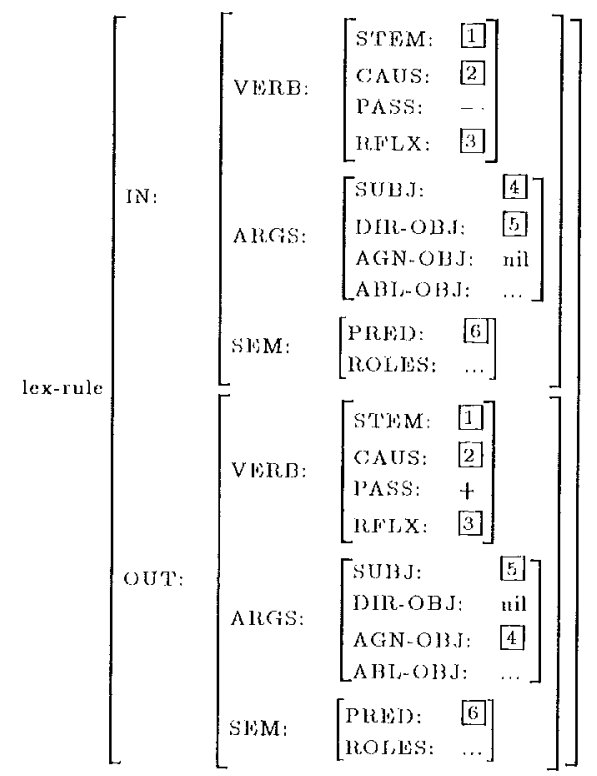

Figure 4: The simplified passivization rule for transitive verbs

ligures 4 and 5 show two of the simpler lexical rules.

\subsection{Examples}

In this section we present a fow examples that show how one can lescribe a given verb sense. For the first example the following constraints are employed:

1. VERB-IS-YE is a constraint corresponding to [VRRB: I S'TEM: "ye"]

2. VERB-TAKES-NO-PASSIVE-NO-REFLEXIVE is

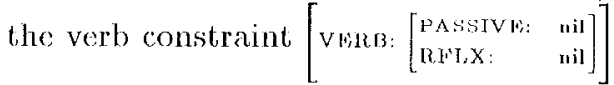

3. DIR-OBJ-HAS-NO-POSS is the morphological constraint [ARGS: | Mmeons: | poss: none]

4. DIR-OBJ-IS-ACC is the morphological constraint [ARGS: |DIR-OBJ: |CASE: acc]

5. NO-DATIVE-OBL-OBJ is the argument cooccurrence constraint [Ancis: |DAT-OIBL: nil]

6. SUBJECT-IS-HUMAN is the semantic constraint [ARGS: |SUBJFOT: |HWAD: | SWM: human]

7. DIR-OBJ-HEAD-LEX-KAFA is a lexical constraint [ARGS: |DIR-OBJ: |HFAD: |LEX: "kafa"]

8. SEM-GET-MENTALLY-DERANGED is the feature structure for the semantics portion

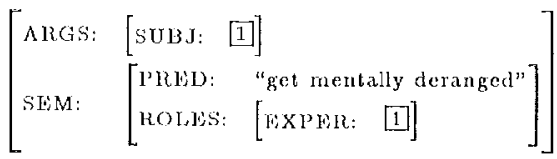

We can then express the constraint for the verb sense by unifying (denoted by \& in 'Tl's) all the 


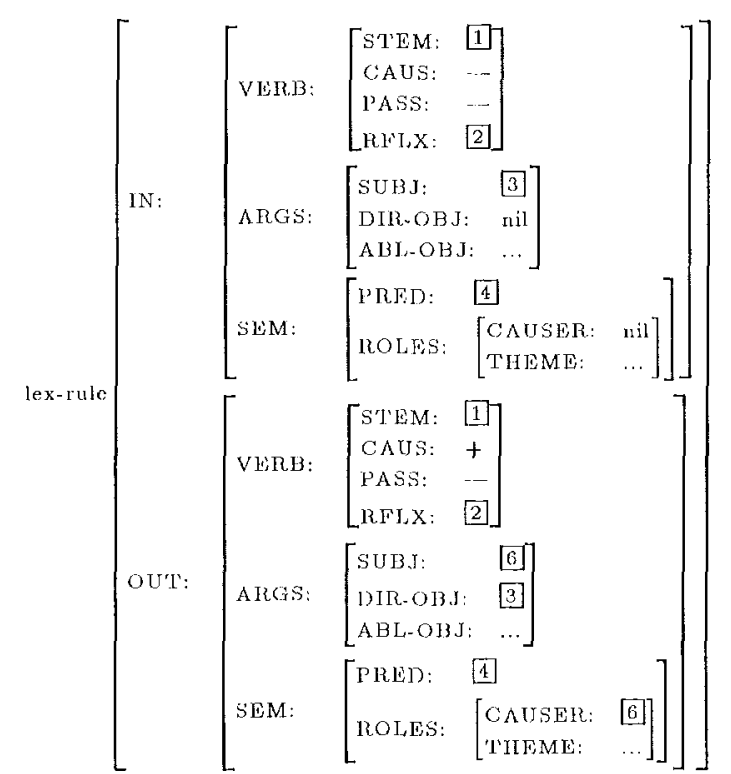

Tigure 5: The simplified causation rulc for intransitive verbs

constraints above:

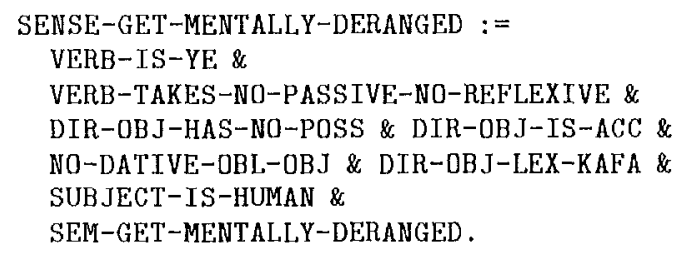

The rosulting constraint when unified with partially specified case frame entry . an entry where only the argument and verb entries have been specificd, will supply the unspecified SEM component(s). That is, when a partially specified case lrame such as

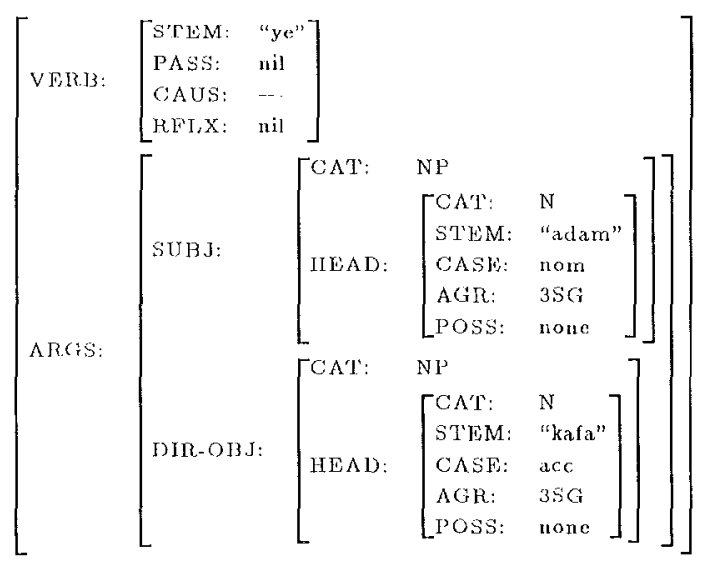

unifies successfully with the given constraint above, the unspecified portion will be properly instantiated with the experiencer being coindexed with the subject in the arguments.
As a second example, consider the default sense of ye corresponding to eat (something). 'The constraints are:

1. VERB-IS-YE is the verb constraint [VERB: I STEM: "ye"]

2. VERB-TAKES-NO-REFLEXIVE is the verb constraint [VERR: । R.JTX: nil]

3. NO-DAT-OBL-OBJ is the co-occurrence constraint [ARGS: IDAT-OHT: nil]

4. DIR-OBJ-IS (optional-edible) is the disjunctive argument constraint [NRGS: IDIR-OBJ: $\left\{\begin{array}{ll}{[\text { HEAD: }} & \text { [SFM: edible }]] \\ \text { nil } & \end{array}\right]$

('This is just explanatory, see below for how this is implemented in ITS.)

5. ABL-OBJ-IS (optional-container) is the argument constraint

$\left[\right.$ ARGS: | ABL-OBJ: $\left\{\left[\begin{array}{lll}{[\text { II:AD: }} & {[\text { SLM: container }]}\end{array}\right]\right\}$

6. INST-OBJ-IS (optional-instrument) is the argument constraint;

[AlGS: |INST: $\left.\left\{\begin{array}{ll}{[\text { HIFAD: [SEM: instrument }]} & \text { ril }\end{array}\right]\right\}$

7. SEM-EAT1 is the feature structure for the se mantics portion

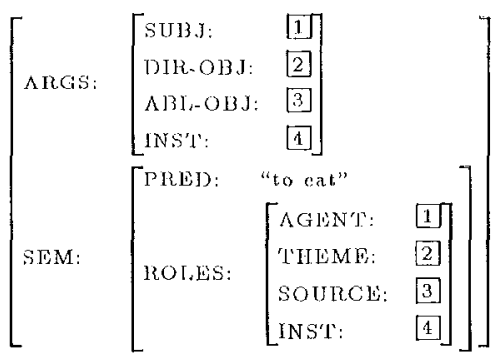

In most cases, there are arguments that are not obligatorily required for resolving a verb scnse. These, nevertheless, have to be constrained, usually on semantic grounds. lor instance the direct object is not obligatory for the basic sense of $y e$, but has to be an edible entity if it is present. We handle these constraints by defining a slightly more complex type hierarchy:

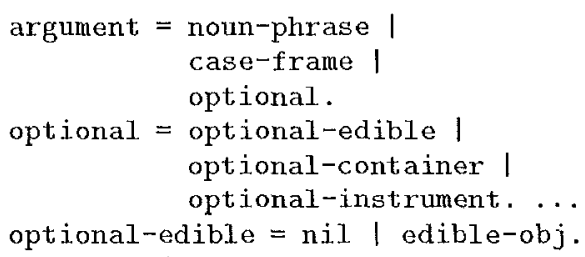

where IS-A-EDTBLE is a constraint of the form [HFad: I sem: edible]. The optional ablative and instrumental objects are defined similarly. ${ }^{4}$ The

\footnotetext{
${ }^{4}$ Note that the surface case constraints for these are defined in the basic definition of the case frame.
} 
sense definition then becomes:

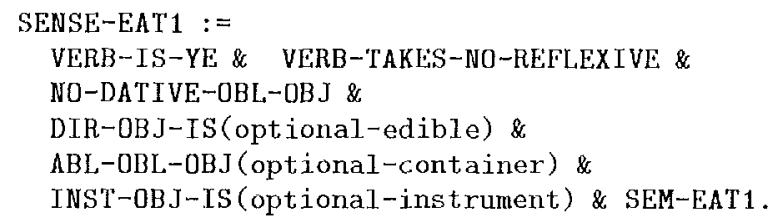

$\Lambda$ s a more complicated example employing nested clauses, we present below the case frarne for the lasit example in Soction 2, where the verb tut (calch) is ased with a clausal subject for a very specific idiomatic usage.

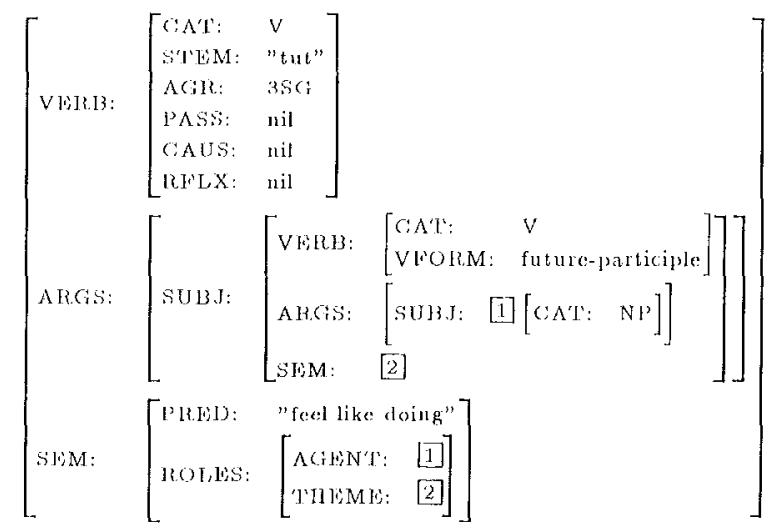

In this case, the sense resolution of the embedded case frame is also performed concurrently with the case frame resolution of the top-level framc.

The last example bolow illustrates the handling of valcucy changing transformations where lexical rules handle argument shullling.

$\begin{array}{lll}\text { Cocuk } & \text { adam } & \text { larafindian } \\ \text { Child } & \text { man } & \text { by } \\ & & \\ \text { karslya } & \text { gecirildi. } & \\ \text { opposite_side } & \text { pass+CAUS } & \\ \text { +DAT } & \text { +PASS+PAST+3SG }\end{array}$

(Ihe child was passed to the opposite side by the man.)

'The ontput for this sontence is prosented on the right.

\section{Conclusions}

'This paper has presented a constraint-based lexicon architecture for representing and resolving verb senses and idiomatic usage in a case frame framework using constraints on different dimensions of the information available. Economy of reprosentation is achieved via sharing of constraints across many verb sense definitions. 'The system has been implemented using the 'TFS system.

\section{Acknowledgments}

'This research was in part funded by a NAIO Scicnce for Stability Phase III Project Grant - 'TULANGUAGL.

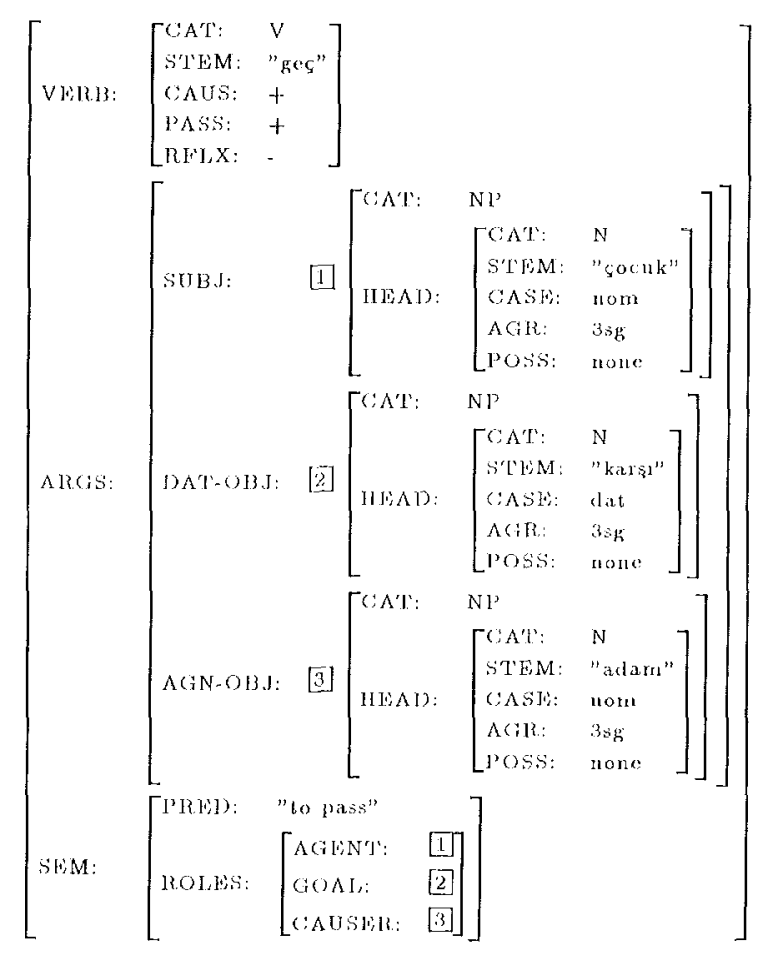

\section{References}

Briscoe, li.J., A. Copestake, and V. de Paiva (eds.). 1993. Inheritance Defeulls and the lexicon. Cambridge University P'ress.

Briscoc, E. J. and J. Carroll 1994. 'Towards Automatic lixtraction of Argument Structure from Corpora 'Tochnical Report, MLI'I'-006, Rank Xerox Research Centre, Grenoble.

Kuhn, J. 1993. Fncoding IIPSG Grammars in THS. Institut für Maschinclle Sprachverarbeitung, Universitä.i Stuttgard, Gormany, March.

Iascarides, A., 'I'. Briscoe, N. Asher, and A. Copestake. 1995. Order Independent and Persistent I'yped Iefault Unification, T'cchnical Report, Cambridge University, Computer Laboratory, March.

Nagao, M., J. T'sujii, and J. Nakamura. 1985. 'The Japanese Govermment Project, for Machine 'Translation. In Compulational Linguistics, volume 11. Aprit-September.

de Paiva, V. 1993. 'Types and Constraints in IKBB. In Briscoo el al. (1993).

Russell, G, $\Lambda$. Ballim, J. Carroll, and S. WarwickArmstrong. 1993. A Practical Approach to Multiple Default Inheritance for UnificationBased Iexicons. In In Briscoe et al. (1993).

'C'schichold, C. 1995. Finglish Multi-word Lexenes In $\Lambda$ Lexical Database. In Procedings of the Lexicon workshop of thSSIII'95, Scventh liuropean Summer School in logic Language and Information, August 